\title{
Myastenia gravis tanılı hastada sugammadex kullanımı
}

\section{Sugammadex use in a patient with myastenia gravis}

\author{
Ebru Biricik
}

Çukurova Üniversitesi Tıp Fakültesi, Anesteziyoloji ve Reanimasyon Anabilim Dalı, Adana, Türkiye

\section{Öz}

Myastenia gravis nöromüsküler kavşağı tutan otoimmün bir hastalıktır ve bu tanıyı alan hastalarda operasyon sonrası solunum yetmezliği gelişme riski vardır. Aynı şekilde kronik obstrüktif akciğer hastalığı varlığında da postoperatif solunum yetmezliğinin gelişebileceği bilinmektedir. Ancak steroid yapılı nondepolarizan kas gevşeticiler ve bu kas gevşeticilerin etkilerini geri döndürmek için kullanılacak sugammadeks olası postoperatif solunum yetmezliği riskini en aza indirmektedir. Bu olgu sunumunda, acil laparotomi için roküronyum ile genel anestezi uygulanan myastenia gravis ve kronik obstrüktif akciğer hastalığı tanıları olan hastada sugammadeks ile postoperatif solunum yetmezliğinin önlenebildiği başarılı bir genel anestezi uygulamasını sunmak istedik.

Anahtar Sözcükler: Myastenia gravis, sugammadex, roküronyum.

\section{Abstract}

Myastenia gravis is an autoimmune disease involving the neuromuscular junction and patients receiving this diagnosis have a risk of developing postoperative respiratory failure. Similarly, the presence of chronic obstructive lung disease is known to be associated with postoperative respiratory failure. However, steroidal non-depolarising muscle relaxants and sugammadex to reverse their muscle-relaxing effects minimize the risk of postoperative respiratory failure. In this case report, we wanted to present a successful application of general anesthesia with rocuronium for emergency laparotomy in a patient with myasthenia gravis and chronic obstructive pulmonary disease in whom postoperative respiratory failure could be prevented by using sugammadex.

Keywords: Myastenia gravis, sugammadex, rocuronium.

\section{Giriş}

Myastenia gravis (MG), nöromüsküler kavşakta postsinaptik asetin kolin reseptörlerine karşı antikorların varlığı ile karakterize bir hastalıktır. Nöromüsküler son plakta sinyal iletiminin bozulması yorgunluk ve kas güçsüzlüğü ile kendini gösterir. Bu nedenle nöromüsküler blokaj uygulanan bu hastalarda postoperatif dönemde solunum yetmezliği riski yüksektir. MG tanılı hastalar operasyon sırasında ve derlenme süresince nöromüsküler monitörizasyonla izlenmeli olası bir rezidüel bloğa karşı hazırlıklı olunmalıdır (1). MG'de depolarizan kas gevşeticilere karşı direnç gözlenir. Non-depolarizan kas gevşeticiler ile ise uzamış nöromüsküler blokaj oluşabilir (2). MG tanılı hastalarda nöromüsküler bloker ajan seçiminde steroid yapılı olanların (veküronyum ve roküronyum) tercih edilmesi nöromüsküler etkinin ortadan kaldırılmasında sugammadeks kullanılması açısından önemlidir.

\section{Yazışma Adresi: Ebru Biricik}

Çukurova Üniversitesi Tıp Fakültesi, Anesteziyoloji ve Reanimasyon Anabilim Dalı, Adana, Türkiye

Makalenin Geliş Tarihi: 10.11.2014 Kabul Tarihi: 23.01.2015
Sugammadeks modifiye $\mathrm{\gamma}$-siklodextrin yapıda bir ilaç olup enkapsülasyon ile steroid yapılı nöromüsküler blokerlerin etkilerini ortadan kaldırmaktadır (3).

\section{Olgu Sunumu}

On beş yıldır myastenia gravis tanılı olan 50 yaşındaki kadın hasta (ağırlık $75 \mathrm{~kg}$, boy $158 \mathrm{~cm}$ ) akut batın tanısı ile acil servise başvurdu. Anamnezinde hastalığının aktif olduğu dönemde jeneralize kas güçsüzlüğü olduğunu tanımlıyor, 3 yıl öncesine kadar pridostigmin $60 \mathrm{mg}$ tablet 4x1/gün kullanma öyküsü mevcut, klinik olarak düzelmesi üzerine ilacı kullanmayı kendi isteği ile bırakmıs. Aynı zamanda 10 yıldır $\mathrm{KOAH}$ nedeniyle düzensiz olarak inhaler $\beta 2$ sempatomimetik kullanmış. Operasyon öncesi nörolojik muayenesinde; bilinç açık koopere, pupilleri izokorik, periferik kas gücü tam, yüzeyel duyuları normal, serebellar testler normal bulundu, patolojik refleks saptanmadı. Solunum sistemi muayenesinde her iki hemitoraksta yaygın kaba raller duyuldu. Laboratuvar tetkiklerinde lökositoz (nötrofil hakimiyeti) mevcuttu. Akciğer grafisinde bronkoalveoler dallanmada artış ve alt zonlarda infiltratif görünüm izlendi. Yaklaşık 5 saatlik açlık süresi olan hasta acil 
şartlarda operasyon odasına alındı ve EKG, pulseoksimetre, noninvaziv tansiyon arteriyel ve train of four (TOF) ile monitörize edildi. Kalp atım hızı 90/dk, TA: 130/90 mmHg, SpO2 \%94 olarak ölçülen hastaya sol el üzerinden damaryolu açıldıktan sonra $2 \mathrm{mg} / \mathrm{kg}$ propofol ile anestezi indüksiyonuna başlandı. Sol önkol ulnar sinir trasesi üzerine yerleştirilen elektrotlar ile nöromüsküler fonksiyonlar izlemek için TOF kalibrasyonu yapıldı ve roküronyum $0.6 \mathrm{mg} / \mathrm{kg}$ ve fentanil $100 \mu \mathrm{g}$ iv uygulandı. TOF değeri 0 olduğunda entübe edildi. Anestezi idamesi, desfluran \%4 ve $\mathrm{O}_{2}-\mathrm{N}_{2} \mathrm{O} \% 50-50$ konsantrasyonlarda sağlandı. İntraoperatif dönemde aminofilin $240 \mathrm{mg}$ iv uygulandı. Operasyonda batın eksplorasyonu ve apendektomi yapıldı. Operasyonun 40. dakikasında TOF değeri \%45 olarak ölçüldü ve ek doz $10 \mathrm{mg}$ roküronyum iv uygulandı. Postoperatif analjezi amacıyla $2 \mathrm{mg} / \mathrm{kg}$ tramadol iv yapıldı. Bir saat 5 dakika süren operasyonun bitiminde TOF değeri 0 olarak ölçüldü ve $2 \mathrm{mg} / \mathrm{kg}$ sugammadeks iv uygulandı. \%90 TOF değerine 242 saniye sonra ulaşıldı. Yeterli kas tonusuna ulaşıldığında ve solunum eforu yeterli olduğunda hasta ekstübe edildi. Bilinci açık ve koopere idi, başını 5 saniye süre ile kaldırabildiği gözlendi. Operasyon sonrası gözlem amacıyla yoğun bakımda 24 saat izlendi. Oda havasında SpO2 değerleri \%94-97 arasında değişmekteydi. Vital bulgularının ve kas tonusunun normal olması, komplikasyon yaşanmaması üzerine genel cerrahi servisine nakledildi.

Hastadan tıbbi verilerinin yayınlanabileceğine ilişkin yazılı onam belgesi alındı

\section{Tartışma}

MG tanılı hastalar anestezi uygulamalarında kas gücü ve postoperatif solunum yetmezliği açısından özellikli hastalardır. Bu hastalarda uzamış postoperatif solunum yetmezliği görülebilir (4). Preoperatif değerlendirmenin yanında peroperatif anestezi yönetimi ve postoperatif bakım dikkat ve yakın monitörizasyon gerektirmektedir.
Hastamızda, hem MG hem de KOAH tanısı nedeniyle postoperatif dönemde solunum yetmezliği gelişebileceği ön görülmekteydi. Myastenik hastalarda nöromüsküler monitörizasyon uygulamasının uzamış nöromüsküler blokaj açısından gerekli olduğunu düşünmekteyiz. Pridostigmin tedavisi alan hastalarda operasyon sonunda uygulanacak pridostigminin nöromüsküler bloğun geri döndürülmesinde başarısız olabileceği düşünülmektedir. $\mathrm{Bu}$ da asetilkolin reseptörlerinin maksimum baskılanmasına bağlanmaktadır (5). Steroid yapılı nondepolarizan kas gevşeticilerin etkilerini literatürde sugammadeksin myastenik hastalarda güvenle uygulandığı gösterilmiştir (6). Steroid yapılı nöromüsküler blokerleri myastenik hastalarda indüksiyon dozunun altında dozlarda uygulayıp, TOF değerlerini kontrol ederek aralıklı dozlarla indüksiyonu tamamlayan olgu sunumu literatürde mevcuttur (7). Bu olguda biz hastanın açlık süresinin sınırda olması nedeniyle hızı entübasyon amacıyla $0.6 \mathrm{mg} / \mathrm{kg}$ dozda roküronyum kullandık. Acil hızlı entübasyon için roküronyumu 0.9-1.2 $\mathrm{mg} / \mathrm{kg}$ dozlarda uygulanmasını tavsiye eden yayınlar da mevcuttur (8). Kas gevşeticisiz entübasyonun uygulandığı MG olgusu da vardır (9). Ancak sugammadeksin anestezi pratiğine girmesi ile birlikte kas gevşeticisiz entübasyona gerek kalmadığını düşünmekteyiz. Bizim uygulamamızda olduğu gibi $2 \mathrm{mg} / \mathrm{kg}$ sugammadeks ile yeterli nöromüsküler ileti sağlayan ve postoperatif komplikasyon gözlenmeyen olgular da izlenmiştir $(6,10)$. Sugammadeksin MG tanılı hastalarda güvenle kullanılmasına rağmen, rezidüel blok açısından postoperatif dönemde hastaların yoğun bakım şartlarında takip edilmesi önerilmektedir. Sonuç olarak, myastenia gravis ve $\mathrm{KOAH}$ tanılı hastalar postoperatif solunum yetmezliği riski taşımaktadırlar ve genel anestezi uygulanacak bu hastalarda nöromüsküler bloker olarak roküronyum, nöromüsküler blokajın tersine döndürülmesinde ise sugammadeks kullanılmasının postoperatif solunum yetmezliği riskini en aza indirdiğini düşünmekteyiz.

\section{Kaynaklar}

1. Blichfeldt-LauridsenL, Hansen BD. Anesthesia and myasthenia gravis. Acta Anaesthesiol Scand 2012;56(1):17-22.

2. Savarase JJ, Caldwell EJ, Lien AC, Miller RD. Pharmacology of muscle releaxants and their antagonists. In: Miller RD (ed). Anesthesia. 5th edition, Phildelphia; 2000;12:447-71.

3. Bom A, Bradley M, Cameron K, et al. A novel concept of reversing neuromuscular block: chemical encapsulation of rocuronium bromide by a cyclodextrin-based synthetic host. Angew Chem Int Ed Engl 2002;41(2):266-70.

4. Petrun AM, Mekis D, Kamenik M. Successful use of rocuronium and sugammadex in a patient with myasthenia. Eur J Anaesthesiol. 2010;27(10):917-8

5. Cardone A, Congedo E, Aceto P, et al. Perioperative evaluation of myasthenia gravis. Ann Ital Chir 2007;78(5):359-65.

6. Unterbuchner C, Fink H, Blobner M. The use of sugammadex in a patient with myasthenia gravis. Anaesthesia 2010;65(3):302-5.

7. Sargın M, Borazan H, Sarıtaş TB, Otelcioğlu Ş. Miyastenia gravis ve sugammadeks kullanımı. GKDA Derg 2013;19(3):136-40.

8. Jensen AG, Callese T, Hagemo JS, Hreinsson K, Lund V, Nordmark J. Scandinavian clinical practice guidelines on general anaesthesia for emergency situations. Acta Anaesthesiol Scand 2010;54(8):922-50.

9. Tagawa T, Sakuraba S, Okuda M. Rapid sequence intubation using Pentax-AWS without musclerelaxants in patients with myasthenia gravis. Acta Anaesthesiol Taiwan 2009;47(3):154-5.

10. Karaman $Y$, Çakmak M, Özkarakaş H, Güvenli Y, Gönüllü M. Myastenia gravisli hastada sugammadeks ile postoperatif mekanik ventilasyon gereksinimi azalır mı? Ege Journal of Medicine 2012;51(1):069-071. 